\title{
ISLAM, BUDAYA INDONESIA, \\ DAN POSISI KAJIAN ISLAM DI PERGURUAN \\ TINGGI ISLAM
}

\section{H. Mastuki HS*}

Subdit Kelembagaan Diktis, Kementerian Agama RI Jakarta

e-mail: larose_bwi@yahoo.com

\begin{abstract}
This article discusses the integration of Islamic values into Indonesian's culture. Seen from the point of view of religion, Indonesia is the largest Muslim nation in the world (the biggest Muslim country in the world). But in the religion - political and ideological, Indonesia is not an "Islamic State ". However, it does not mean Islam is Indonesia "not original ". Difficult to deny that the teachings and values of Islam has contributed much to the formation of Indonesian national culture. On the other hand, the institutionalization of Islamic values is also very powerful form of knowledge and intellectual system of the people, customs and belief systems, national culture, economic systems, up to the formation of Muslim behavior in Indonesia. In short, Islamic values has been fused with the culture of Indonesia. Islamic values have been institutionalized and becomes tradition in Indonesia then experience the dynamics and endless adjustments to this day.
\end{abstract}

\begin{abstract}
Abstrak
Artikel ini membahas tentang integrasi nilai-nilai Islam ke dalam budaya Indonesia. Dilihat dari sudut pandang agama, Indonesia adalah bangsa Muslim paling besar di dunia (the biggest muslim country in the world). Tetapi secara religio-politis dan ideologis, Indonesia bukanlah "Negara Islam”. Meski demikian, bukan berarti Islam Indonesia “tidak asli”. Sulit dipungkiri bahwa ajaran dan nilai-nilai Islam telah menyumbang banyak pada pembentukan budaya bangsa Indonesia. Di sisi lain, pelembagaan nilai-nilai Islam juga amat kuat membentuk sistem pengetahuan dan intelektual umat, adat istiadat dan sistem kepercayaan, budaya bangsa, sistem ekonomi, hingga pada pembentukan prilaku Muslim di Indonesia. Singkatnya, nilai-nilai Islam telah bersenyawa dengan budaya bangsa Indonesia. Nilai-nilai Islam itu kini telah melembaga dan mentradisi di Indonesia dan mengalami dinamika dan penyesuaian yang tiada henti hingga hari ini.
\end{abstract}

Kata Kunci: Budaya Indonesia, kajian Islam, plural.

${ }^{*}$ Penulis adalah Kasubdit Kelembagaan pada Direktorat Pendidikan Tinggi Islam, Kementerian Agama RI; Dosen pada Pascasarjana IAIN Bengkulu, STAIN Jember, STAINU Jakarta, IAIN Tulung Agung dll. 


\section{A. PENDAHULUAN}

Prof Dr. Nurcholish Madjid (alm) pernah menyatakan bahwa Indonesia adalah salah satu bangsa paling pluralis di dunia. Memiliki 17.600 pulau baik besar maupun kecil, dihuni maupun tidak, Indonesia adalah negara kepulauan terbesar di dunia, dan negara yang memiliki keragaman sangat tinggi dalam hal suku, ras, bahasa, budaya, dan agama. Sebagaimana diakui oleh antropolog Robert Hefner dalam bukunya The Politics of Multiculturalism: Pluralism and Citizenship in Malaysia, Singapore and Indonesia (2001), keragaman budaya dan perbedaan adalah kenyataan yang tak bisa dipungkiri di Indonesia. Ada sekitar 656 kelompok etnis, besar dan kecil, hidup di wilayah Indonesia, memiliki budaya, tradisi, dan adat istiadat yang berbeda-beda menjadikan Indonesia sebagai negara dengan kebudayaan yang sangat beragam.

Tidak kalah pentingnya, kelompok etnis yang berbeda itu berbicara dalam 746 bahasa dan dialek lokal yang berbeda, meskipun saat ini kira-kira 726 bahasa itu di ambang kepunahan (on the edge of extinction), tetapi masih ada 13 bahasa yang tetap survive, diucapkan oleh kurang lebih 1 juta orang. Berkenaan dengan bahasa ini, Indonesia beruntung karena telah berhasil menetapkan bahasa Indonesia (yang berasal dari bahasa Melayu) menjadi bahasa nasional yang ditetapkan pada Sumpah Pemuda (Youth Pledge) tanggal 28 Oktober 1928.

Dilihat dari sudut pandang agama, Indonesia adalah bangsa Muslim paling besar di dunia (the biggest muslim country in the world). Tetapi secara religio-politis dan ideologis, Indonesia bukanlah "Negara Islam". Indonesia adalah negara yang didasarkan kepada ideologi resmi yang disebut Pancasila: (1) kepercayaan kepada Tuhan Yang Maha Esa atau disebut monoteisme; (2) kemanusiaan yang adil dan beradab; (3) persatuan Indonesia; (4) demokrasi; dan (5) keadilan sosial. Soekarno, presiden Republik Indonesia yang pertama, dikenal sebagai penemu Pancasila. Ia menawarkan kelima dasar di atas sebagai modus vivendi antara nasionalisme sekuler yang disuarakan kaum nasionalis dan gagasan Negara Islam yang dituntut oleh para politisi berorientasi Islam. Para pemimpin Islam menerima Pancasila ketika ia dicantumkan pada Pembukaan UUD 1945 dan dianggap tidak bertentangan dengan ajaran Islam.

Penerimaan Pancasila bagi Muslim adalah satu hal sangat penting dan merupakan akar pluralism Islam Indonesia (Indonesian Islamic roots of pluralism). Bagi kebanyakan kaum Muslim, dilihat dari perspektif al-Qur'an, Pancasila merupakan titik temu (common platform, kalimat-un sawâ') di antara berbagai kelompok agama yang berbeda. Sebagaimana perintah Allah yang dialamatkan kepada Nabi Muhammad SAW:

'Katakanlah wahai para pengikut kitab suci, marilah menuju kepada kalimat-un sawa' (kalimat atau ajaran yang sama) antara kami dan kami, yaitu bahwa kita tidak menyembah kecuali Allah, dan tidak mempersekutukanNya kepada sesuatu apapun juga, dan sebagian dari kita tidak mengangkat sebagian yang lain selaku tuan-tuan selain daripada Allah... (QS 3:64)”. 


\section{B. PELEMBAGAAN NILAI ISLAM DI INDONESIA}

Meskipun merupakan salah satu bangsa Muslim terbesar di dunia, Indonesia adalah bangsa yang paling sedikit mengalami Arabisasi dibanding negara-negara Muslim besar lainnya. Selain itu, secara geografis Indonesia terletak sangat jauh dari tanah suci Makkah dan Madinah, pusat kelahiran Islam. Meski demikian bukan berarti Islam Indonesia "tidak asli". Sulit dipungkiri bahwa ajaran dan nilai-nilai Islam telah menyumbang banyak pada pembentukan budaya bangsa Indonesia. Pengaruh Islam dalam budaya Indonesia ini, menurut Nurcholish Madjid bisa dibandingkan dengan pengaruh Islam terhadap budaya Barat (Madjid, XII/1998). Sebagai contoh beberapa kata pinjamana Arab dalam bahasa Inggris, misalnya admiral, alchemy, alcohol, algebra, algorithm, alkali, cipher, coffee, cotton, lute, magazine, muslin, nadir, sofa, tariff, zenith, dan zero.

Pengaruh Islam makin terasa ketika bahasa Melayu dari provinsi Riau, Sumatera, dijadikan sebagai bahasa nasional dan resmi Republik Indonesia. Sebagai bahasa yang jauh lebih egalitarian dan kosmopolit daripada bahasa Jawa, meskipun tidak lebih kaya darinya, bahasa Melayu adalah bahasa kebudayaan Islam Asia Tenggara, kurang lebih dapat disejajarkan dengan posisi bahasa Arab di dunia Arab dan bahasa Persia di dunia Islam Asia Kontinental.

Sebagai bahasa nasional Negara Indonesia, yang karena itu disebut "bahasa Indonesia", bahasa Melayu memainkan peran sangat besar dalam membawa masuk pengaruh Islam ke dalam budaya politik modern Indonesia. Sebagai sebuah nomenklatur, budaya politik itu memuat banyak kata Melayu yang asalnya merupakan pinjaman dari kata-kata Arab, seperti rakyat (ra'yab), majelis (majlis), dewan (dîwân), mufakat (muwâfaqab), wajib (wâjib), bina (binâ'), hukum (bukm),amal ('amal), mahkamah (mabkamah), tertib (tartib), makmur (ma'mûr), wakil (wakîl), daerah (dâirah), wilayah (wilâyah), resmi (rasmî), dan seterusnya.

Kata serapan bahasa Arab jauh lebih banyak -bahkan mempengaruhi sistem kemasyarakatan dan kenegaraan. Jika kita periksa pada perumusan nilai-nilai Pancasila saja, unsur-unsur Islam itu akan segera tampak dalam konsep-konsep tentang adil, adab, rakyat, hikmat, musyawarah, dan wakil. Lebih dari itu, dapat disebutkan bahwa rumusan sila keempat Pancasila itu sangat mirip dengan ungkapan dalam bahasa Arab yang sering dijadikan dalil dan pegangan para ulama, ra'sul bikmah al-masyurah (pangkal kebijaksanaan adalah musyawarah). (Bdk. Rahardjo, 1993)

Jauh sebelum Indonesia merdeka, pengaruh nilai-nilai Islam dalam pemikiran politik atau ketatanegaraan telah dipraktikkan oleh kerajaan Islam seperti tercermin pada tiga nilai universal yakni adil, syara', dan musyawarah. Adil, misalnya sudah ditulis dalam mata uang Aceh pada abad ke-13. Pepatah "raja adil raja disembah, raja lalim raja disanggah" menunjukkan kuatnya konsep adil. Syara' menggantikan kekuasaan mutlak perorangan raja. Ada suatu sistem yang disebut syara' yang harus ditaati bersama. Di Minangkabau ada ungkapan, "Adat basandi syara', syara' basandi kitabullah" (Adat bersendi syara' (agama), syara' bersendi Kitabullah (al-Qur'an)". Kemudian musyawarah juga menjadi praktik di kerajaan-kerajaan Islam di luar Jawa (Kuntowijoyo, 2001). 
Di Jawa -terutama Jawa Tengah dan Jawa Timur-penetrasi nilai-nilai Islam awalnya menghadapi resistensi kebudayaan dari Hinduisme-Buddhisme yang sudah mapan sebelumnya. Karena itu, nilai syara', adil, dan musawarah kurang dikenal atau dipraktikkan di kerajaan-kerajaan Jawa. Malahan, di Jawa konsep mistik "manunggaling kawula-Gusti" yang berasal dari pantheisme ("dunia terlebur dalam Tuhan") dan monisme ("Tuhan terlebur dalam dunia") mendapat bobot politik yang kuat. Dari konsep itu timbullah tatanan politik yang merujuk pada kekuasaan mutlak raja. Pada kerajaan-kerajaan Islam pun, konsep ini begitu kuat sehingga Sultan diberi gelar "panatagama" (penanggung jawab bidang agama) atau "khalifatullah" (duta Tuhan) yang merepresentasi konsep "Gusti" (Raja) berhadapan dengan kawula (rakyat). Hal ini misalnya tercermin pada gelar Raja Mataram Islam pertama, Danang Sutawijaya (1587-1601) yakni Panembahan Senopati ing Alaga Sayidin Panatagama Khalifatullah Tanah Jawa.

Meski demikian, hampir semua sistem ketatanegaran yang dianut kerajaan-kerajaan Islam yang berdiri di seluruh Nusantara sejak abad ke-13/15 seperti Samudera Pasai, Aceh Darussalam, Demak, Mataram, Ternate, dan Bone dipengaruhi dan didasarkan pada ajaran Islam. Kitab kitab Nashihatul Muluk karya Imam Ghozali sangat berpengaruh sehingga mengilhami lahirnya kitab seperti Bustanus Salatin karya Syekh Nuruddin ArRaniri. Di Jawa terdapat kitab yang sama, beraksara Jawa, yaitu serat Tajus Salatin, selain Adabus Salatin, Ikbbarul Muluk dan sebagainya. Semuanya itu menjadi rujukan para raja dalam menyusun undang-undang dan melaksanakan kebijakan pemerintahan (Mun'im, 2010). Pada abad ke 19 Raja Surakarta Mangkunegara IV yang seangkatan dengan Ronggowarsito mengarang Kitab Wedhatama (Ajaran Luhur) yang dijadikan pelajaran bagi para pangeran calon raja. Selain itu juga ditulis kitab yang sama bernama Wulangreh.

Selain membahas ketatanegaraan, beberapa kitab tadi kemudian diterjemahkan secara teknis menjadi berbagai hukum dan peraturan kerajaan. Dari sini lalu muncul lembaga peradilan dan karena itu ada Qodli Qudlot (Hakim Agung) serta patra penghulu yang menangani pelaksanaan hukum dan peradilan. Sampai akhir abad ke-19 Kesultanan Sambas, Kalimantan Barat misalnya masih menjalankan sistem hukum secara seksama terdiri dari sistem peradilan mulai dari paling rendah Balai Bidai, kemudian Balai Raja, dan yang tertinggi Balai Kanun (Mahrus, 2003). Sistem politik yang kuat seperti itu pada gilirannya membentuk apa yang oleh Kuntowijoyo (1997) disebut civic culture (budaya bernegara).

Penetrasi dan pelembagaan nilai-nilai Islam sesungguhnya jauh lebih rumit (complicated) seiring dengan proses Islamisasi di Nusantara hingga Indonesia merdeka. Selain berpengaruh pada sistem hukum dan ketatanegaraan, nilai-nilai Islam juga berpengaruh terhadap munculnya lembaga-lembaga sosial Islam (Islamic social institutions) seperti wakaf, baitul mal, filantropisme, dan pendidikan Islam yang dimulai dari pesantren, tajug, atau langgar (modifikasi dari sistem pendidikan Hindu-Budha sebelumnya: sanggar, padepokan atau pertapaan), diniyah, surau, meunasah/dayah, kemudian pada awal abad ke-20 muncul madrasah yang didirikan berbagai organisasi Islam yang bergabung dalam pergerakan nasional. Lalu hadir pula perguruan tinggi Islam pada masa awal kemerdekaan sampai 
mengalami perkembangan signifikan tahun 1960-an. Hingga hari ini, jenis dan bentuk lembaga-lembaga sosial ini mengalami eskalasi dan sofistikasi yang luar biasa.

Proses Islamisasi di Nusantara juga membentuk solidaritas "nasional" dimana seluruh wilayah yang kemudian menjadi "Indonesia" diikat dalam satu kesatuan, sebuah network. Jaringan itu terbentuk terutama sesudah ada diaspora Islam setelah Malaka jatuh ke tangan Portugis pada 1511. Persamaan agama, budaya dan lingua franca (Melayu) menjadikan jaringan agama sebagai proto-nasionalisme. Islam masuk ke Nusantara dibawa oleh para pendakwah dari Champa (Vietnam), India, Samarkand, Cina dan lain-lain. Pembawa Islam di Palembang adalah Ario Abdillah yang merupakan putra Brawijaya V, raja Majapahit. Penyebar Islam di Lombok adalah Sunan Prapen yang berasal dari Giri. Raja Islam pertama di Madura Barat belajar agama dari Sunan Kudus. Banjarmasin mengenal Islam karena hubungannya dengan Demak. Ternate menjadi Islam juga lantaran Giri. Tapi berkat kerajaan Ternate Islam lalu menyebar ke Raja Ampat di Papua. Perkembangan Islam di Makassar pun dapat ditelusuri karena hubungan dengan Ternate. Syekh Yusuf al-Makassari menjadi guru di Banten, dan dibuang Belanda ke Cape Town, Afrika Selatan karena perlawanannya bersama orang-orang Banten (Bdk. Kuntowijoyo, 1997).

Ide tentang agama sebagai proto (gerakan)-nasionalisme ini menemukan momentum kembali pada gerakan modernisme Islam di Indonesiayang diwakili SDI (Sarekat Dagang Islam) yang berdiri tahun 1911. Menurut Yudi Latif (2005), untuk pertama kalinya kata "Islam" secara eksplisit digunakan sebagai nama sebuah perhimpunan. Hal ini mengindikasikan bahwa Islam telah diaktifkan sebagai basis identitas kolektif dan sebagai ideologi bagi proto-nasionalis. Tidak lama setelah itu gerakan ini dilanjutkan oleh Sarekat Islam, disusul kemudian cikal bakal organisasi sosial keagamaan yang hingga kini masih tetap eksis, yakni Muhammadiyah, Persatuan Islam (Persis), Mathla'ul Anwar, Persatuan Oemat Islam (POI), Nahdlatul Ulama (NU), dan Tarbiyah Islamiyah (Perti).

Pelembagaan nilai-nilai Islam juga amat kuat membentuk sistem pengetahuan dan intelektual umat, adat istiadat dan sistem kepercayaan, budaya bangsa, sistem ekonomi, hingga pada pembentukan prilaku Muslim di Indonesia. Singkatnya, nilai-nilai Islam telah bersenyawa dengan budaya bangsa Indonesia.

Sistem pengetahuan dan intelektual umat Islam Indonesia hari ini (sebagai little tradition) sesungguhnya berakar kuat pada tradisi Islam besar (great tradition). Pada aspek ini imperasi al-Qur'an untuk mengembangkan ilmu sangat kuat mendorong umat Islam berkelana mempelajari Islam hingga ke pusat Islam, terutama Haramain (Makkah dan Madinah). Penelusuran terhadap geneologi pemikiran para ulama sejak abad ke-16 hingga 19 menunjukkan gairah intelektualisme itu.

Sejumlah ulama' asal Nusantara memiliki reputasi internasional, menulis karya-karya jenius dengan bobot akademik tinggi, seperti Hamzah Fansuri, Nuruddin al-Raniri, Syekh Abdurrauf al-Sinkili (Syah Kuala), Syamsuddin Al-Sumatrani, Muhammad Arsyad alBanjari, Muhammad Nafis Al-Banjari, Abdusshamad Al-Palimbani, Nawawi Al-Bantani, Mahfudh At-Tirmasi, Yasin Al-Padangi, Raja Ali Haji, Kiai Ihsan Jampes, Kiai Soleh Darat Al-Samarangi, hingga Kiai Mutamakkin dan Muhammad Hasyim Asy'arie (Mastuki 
[Ed], 2006). Sayangnya, karya-karya mereka kurang populer dan tidak familiar di perguruan tinggi Islam, termasuk STAIN/IAIN dan UIN. Kurangnya perhatian pada bidang ini menyebabkan masih sedikitnya publikasi dan karya-karya ilmiah dosen perguruan tinggi Islam yang menjadikan naskah Islam Melayu-Nusantara sebagai bahan kajian atau riset.

Penemuan artefak-artefak naskah (manuscript, makbthûthat) di beberapa wilayah Indonesia, atau umumnya Melayu-Nusantara, menunjukkan bahwa persebaran naskah Islam berjalan beriringan dengan perkembangan komunitas-komunitas Muslim yang menempati wilayah-wilayah Indonesia atau Melayu-Nusantara. Bukti itu ditandai melalui tulisan-tulisan manuskrip yang menggunakan bahasa lokal seperti Jawa, Sunda, Melayu, atau arab pegon yang menjadi bahasa komunikasi bagi sebagian besar Muslim MelayuNusantara. Sejumlah kitab fikih, tasawwuf, tafsir, dan hadits ditulis dalam bahasa lokal Nusantara.

Ribuan bahkan puluhan ribu manuskrip karya intelektual itu sebagian didesiminasi melalui pewarisan dari generasi ke generasi terutama pengajaran di pesantren, dan sebagian lainnya masih tersimpan dan tersebar di berbagai tempat di wilayah Indonesia. Salah satu sumber menyebutkan, di Aceh saja diperkirakan terdapat 10.000 naskah Islam sebelum terjadinya tsunami. Karya-karya serupa dapat ditemukan di berbagai wilayah Nusantara seperti Banten, Riau, Jawa Tengah, Yogyakarta, Jawa Timur, Banjarmasin, Palembang, Lampung, Nusa Tenggara Barat, Makassar, Gowa, Bone, Ternate, dan sebagainya. Keberadaan manuskrip itu satu sisi menunjukkan keterkaitan intelektual Islam Indonesia dengan pusat atau asal Islam di Timur Tengah. Sisi lain, kitab-kitab karya ulama' itu telah membentuk sistem pengetahuan umat terhadap ajaran yang terpelihara hingga hari ini, masa kita kini. Bisa dibayangkan bagaimana jika manuskrip-manuskrip itu tidak direproduksi dan diwariskan, maka umat Islam Indonesia akan mengalami keterputusan mata rantai pengetahuan tentang Islam. Begitu kayanya naskah Islam Nusantara ini menjadi peluang dan tantangan bagi perguruan tinggi Islam.

\section{PERSINGGUNGAN ISLAM DAN BUDAYA LOKAL}

Kenyataan bahwa Islam yang datang ke Indonesia dibawa oleh para Sufi, menyebabkan Islam pada masa awal-awal banyak berkompromi dengan budaya lokal. Pertemuan Islam dengan budaya lokal ini sering disalahfahami sebagai penyebab kurang murninya Islam Indonesia. Namun perlu ditegaskan bahwa tasawuf yang berkembang di Indonesia adalah tasawuf yang berpadu dengan syariah secara seimbang (lih. Azra, 1994) Maka tarekat yang berkembang adalah tarekat yang sejalan dengan pandangan itu, seperti tarekat Qadiriyah, Naqshabandiyah, dan Syattariyah. Tarekat ini dianggap mu'tabarah karena memiliki silsilah yang sinambung hingga Nabi Muhammad SAW dan secara isi tidak bertentangan dengan syariat.

Beberapa ciri Islam sufistik dapat dikenali dari ekspresi keagamaan Muslim yang masih lestari sampai saat ini. Pertama, penghormatan pada guru, baik masih hidup maupun yang sudah meninggal. Penghormatan ini melahirkan tradisi ziarah kubur ke makam para ulama dan wali berkembang subur di kalangan umat Islam Indonesia. Dalam ziarah ini 
pelaku membacakan tahlil dan tawasul untuk mendoakan arwah ulama atau wali, sebagai orang yang dekat dan dikasihi Allah, agar mereka dimohonkan doa kepada Allah. Selain tawasul, pelaku ziarah juga melakukan itibar (mengambil pelajaran) atas perjuangan para wali/ulama dalam menyebarkan Islam.

Kedua, pembacaan shalawat kepada nabi adalah bentuk tawasul paling murni dari Islam Nusantara. Pembacaan ini telah dimodifikasi sedemikian rupa sehingga lahir berbagai macam sholawat, seperti pembacaan Maulid Nabi, diba', barzanji, shalawat munjiyat, manaqib dan lain-lain. Syeh Burhanddin Ulakan di Minangkabau (murid Syekh Nuruddin Ar-Raniri) menciptakan Sholawat Dulang untuk sarana dakwah. Demikian juga Kiai Manshur Shiddiq di Jawa Timur untuk menghadapi kelompok ateis menciptakan Shalawat Badar. Pembacaan selawat ini dilakukan di surau atau langgar setiap malam jum'at atau perayaan lahirnya Nabi Muhamamad saw. Bentuk pembacaan itu adakalanya hanya dalam bentuk lisan, tetapi ada yang diiringi dengan beraneka ragam alat musik missal rebana.

Ketiga, tradisi pembacaan tahlil dan pembacaan Al-Qur'an saat ada orang meninggal dunia. Selain dijadikan sarana mendoakan orang Muslim yang meninggal, tradisi ini juga menjadi sarana pelipur lara bagi keluarga yang ditinggalkan, menggantikan kebiasaan zaman pra Islam yang mengisi acara kematian dengan judi dan pesta minuman keras. Tradisi meratapi si mayit oleh para Wali (penyebar Islam di Nusantara) diganti dengan talqin, sementara kebiasaan judi diganti dengan pembacaan zikir dan tahlil.

Keempat, para Wali melakukan kreasi dalam berdakwah dengan menggunakan berbagai sarana misalnya seni wayang atau pemanfaatan alat tradisional seperti beduk dan kentongan untuk keperluan ibadah umat Islam. Kedua sarana yang selama ini digunakan sebagai pemberitahuan dan tanda akan diselenggarakan pertemuan atau tanda bahaya (tergantung iramanya) dimanfaatkan oleh Wali untuk memberi tahu tanda dimulainya waktu sembahyang, karena adzan saja yang diteriakkan melalui menara belum cukup komunikatif mengingat jarak antara masjid, langgar atau surau dengan rumah penduduk sangat jauh dan berpencaran. Dengan alat bantu berupa bedug dan kentongan yang suaranya bisa didengar di kampung lain memudahkan jadi penanda telah masuknya waktu shalat. Bahkan ukuran beduk dan panjang kentongan diselaraskan dengan kedudukan masjid atau surau dan langgar. Beduk masjid agung berbeda besarnya dengan mesjid biasa. Alat yang dulunya sekadar sarana bantu, kemudian berkembang sebagai penentu status dari masjid yang bersangkutan, dan selanjutnya ini menjadi perwujudan dari Islam di kawasan Nusantara, sehingga tidak sempurna sebuah masjid yang tidak memiliki beduk yang representatif.

\section{KELEMBAGAAN ISLAM DEWASA INI}

Nilai-nilai Islam yang telah melembaga dan mentradisi di Indonesia mengalami dinamika dan penyesuaian yang tiada henti hingga hari ini. Bagi PTAI, seluruh perkembangan Islam Indonesia itu sejatinya dapat menjadi lahan subur penelitian dan bahan kajian yang tak habis-habisnya.

Saya mengatakan bahwa proses islamisasi di Indonesia belum selesai dan akan terus berproses. Pasca Indonesia merdeka, pelembagaan nilai-nilai Islam mengalami sofistifikasi 
kembali dengan kehadiran Kementerian Agama tahun 1946 dalam struktur birokrasi negara Indonesia. Kementerian ini mewadahi kepentingan agama-agama, meskipun agama Islam mendapat tempat yang dominan. Melalui Kementerian inilah pelembagaan nilai-nilai Islam semakin kokoh, dengan varian bentuk seperti lembaga pendidikan (madrasah, diniyah, pesantren, dan perguruan tinggi), peradilan agama, zakat dan wakaf, perkawinan (nikah-talak-cerai-ruju' - NTCR), penyelenggaraan haji dan umroh, hingga akomodasi berbagai simpul dan simbol umat Islam Indonesia seperti Masjid Istiqlal, Baitul Qur'an, Majelis Ulama Indonesia, dan Lajnah Percetakan Al-Qur'an.

Perkembangan Islam era 1980-an hingga kini memperkuat sekali lagi bahwa Islam Indonesia telah menjadi lebih sekedar fungsi ideologis (Madjid, 1997), tetapi juga 'agama mayoritas warga negara Indonesia'. Hubungan agama dan negara semakin erat dan mesra. Berbagai lembaga mengalami perkembangan yang cukup observable, seperti lembaga pendidikan Islam (madrasah, diniyah dan pesantren) yang mengalami penyempurnaan melalui UU no 2 tahun 1989 tentang Sistem Pendidikan Nasional, kemudian diperkuat dengan UU no 20 tahun 2003. Dalam UU ini sistem dan kelembagaan pendidikan Islam sejak MI, MTs, MA sampai STAIN/IAIN/UIN dan PTAIS secara legal diakui dan dijamin eksistensinya sejajar (equivalent) dengan sistem dan kelembagaan pendidikan umum (Azra, 1999). Tambahan lagi, tahun 2012 kedudukan PTAI semakin kuat dengan lahirnya UU nomor 12 tahun 2012 tentang Pendidikan Tinggi.

Beberapa peneliti menyebutkan bahwa perkembangan lembaga/satuan pendidikan Islam di Indonesia memiliki keunikan (distingsi) yang tidak ditemukan di masyarakat bangsa lain, di Timur maupun Barat. Pesantren tidak ada padanannya dengan sistem pendidikan yang tumbuh dan berkembang di Timur Tengah sekalipun. Pesantren adalah hasil kreatifitas dan produk asli Indonesia (indigenous education). Madrasah, meskipun ada kesamaan nama dengan lembaga pendidikan di negara lain, namun madrasah di Indonesia memiliki ciri yang unik. Mengajarkan agama secara modern juga pendidikan umum. Keunikan itulah yang dalam banyak hal menjadi daya tarik para pengkaji dan peneliti berbagai negara untuk mengetahui lebih jauh seperti apa lembaga pendidikan pesantren, madrasah, dan perguruan tinggi Islam di Indonesia.

Perguruan tinggi agama Islam (PTAI) di Indonesia layak menjadi barometer pendidikan tinggi Islam dunia. Saat ini terdapat 621 PTAI (negeri dan swasta). Dibandingkan dengan perguruan tinggi Islam di negara lain, jumlah dan sebaran serta kualitas PTAI di Indonesia jauh lebih bagus. Bagi umat Islam Indonesia, kehadiran PTAI merupakan 'berkah' yang berharga. Seperti dikatakan Prof Azyumardi Azra dalam forum AICIS (Annual International Conference on Islamic Studies) di Surabaya 2012, proses islamisasi di Indonesia tidak lepas dari peran besar PTAI. Hal ini mengingat PTAI telah melahirkan intelektual dan intelegensia serta aktivis yang berwawasan Islami. PTAI juga melahirkan pemahaman Islam yang progresif, inklusif, moderat dan kompatibel dengan perkembangan masyarakat Indonesia yang sedang berkembang.

Alumni PTAI juga memiliki peran besar dalam proses konsolidasi Islam. Kiai pesantren sekitar 80 hingga 90\% adalah tamatan PTAI. Guru dan pimpinan madrasah 
didominasi lulusan PTAI. Jajaran aparat Kementrian Agama dari pusat hingga daerah mayoritas alumni PTAI. Beberapa penelitian (tracer studies) menunjukkan alumni PTAI saat ini berkiprah di berbagai bidang. Lebih dari itu, PTAI juga melahirkan kelas menengah Muslim yang memiliki kekuatan cukup massif bagi pembentukan masyarakat demokratis. Sadar atau tidak, mobilitas sosial dan mobilitas intelektual Muslim Indonesia adalah berkat kehadiran PTAI.

Perkembangan yang sama juga dapat dilihat pada peradilan agama Islam yang eksistensinya memperoleh penguatan dengan dikeluarkannya UU no 7 tahun 1989; sejajar dengan peradilan lainnya: peradilan negeri, peradilan tata usaha negara, dan peradilan militer. "Penyetaraan" peradilan agama yang merupakan warisan kerajaan-kerajaan Islam di Indonesia ini seakan memenuhi aspirasi sebagian besar umat Islam yang menurut penelitian lebih prefer untuk menyelesaikan perkara menyangkut perkawinan, talak, rujuk, dan warisan melalui peradilan agama.

Kelembagaan Islam lain yang juga mengalami perkembangan fenomenal adalah majelis ta'lim. Di Indonesia, majelis ta'lim kelihatannya merupakan perkembangan lebih lanjut dari 'pengajian' yang berlangsung di masjid, langgar, dan mushalla di masa lalu. Namun dalam tiga dasawarsa terakhir, majelis ta'lim melewati batas-batas tradisionalnya. Jika pengajian di masjid atau langgar memiliki anggota atau jamaah yang sangat longgar, majelis ta'lim cenderung memiliki anggota/jamaah tetap. Jika pada awal tahun 1970-an majelis ta'lim identik dengan lapisan masyarakat bawah yang tradisional, sekarang majelis ta'lim dapat ditemui di lingkungan elit dan perkotaan. Azyumardi Azra (1997) berkesimpulan bahwa majelis ta'lim mempunya peranan penting dalam proses peningkatan pemahaman dan pengamalan Islam di kalangan muslim/ah dewasa (adult learning) yang tak terjangkau oleh lembaga-lembaga pendidikan formal Islam.

Tak kalah menariknya adalah performa jamaah haji Indonesia yang semakin baik dari tahun ke tahun bahkan menjadi new trade mark bagi pelembagaan Islam Indonesia. Pelaksanaan haji Indonesia mempunyai tingkat kepercayaan internasional yang sangat tinggi. Selain jumlah jamaah haji Indonesia yang sangat besar, perhatian negara terhadap penyelenggaraan haji juga sangat baik. Prestasi ini menjadikan Indonesia sebagai contoh terbaik (the best practice) penyelenggaraan haji bagi dunia Muslim. Banyak negara-negara Muslim yang belajar tentang penyelenggaraan haji Indonesia dan telah menandatangani kesepakatan dengan Kementerian Agama. Performa haji sebagai arena "Muktamar Akbar Muslim se-Dunia" itu merupakan ajang promosi yang luar biasa tentang Islam Indonesia di kancah internasional.

Seiring dengan peta politik Islam dunia, Indonesia menempati posisi sangat strategis dan merupakan negara demokratis terbesar di dunia dengan mayoritas penduduknya beragama Islam (the greater moslem country in the world). Pada saat negara-negara Islam Timur Tengah, terutama kasawan Arab Spring, dilanda persoalan politik yang berujung pada suasana kaotik, bangsa Indonesia dengan jumlah penduduk Muslim mayoritas menjadi magnet baru bagi bangsa-bangsa lain sebagai contoh pelaksanaan demokrasi, hubungan antar agama yang harmonis, pluralisme agama, penyelenggaran haji dan umrah, halal 
produk, peran perempuan Muslim (gender in Islam), dan kompatibilitas Islam dan hak-hak asasi manusia (HAM).

Pentingnya Islam Indonesia sebagai "kawasan baru Islam" (di samping ada Islam Timur Tengah, Islam Eropa, Islam Kontinental, dll) dipercaya oleh negara-negara Islam untuk menyelenggarakan even-even internasional tentang Islam. Pada tanggal 11-15 September 2013, Indonesia menjadi tuan rumah Musabaqah Tilawaqatil Qur'an (MTQ) Internasional yang diselenggarakan di Masjid Istiqlal Jakarta. Event internasional ini diikuti oleh 20 negara antara lain Maroko, Brunei Darsussalam, Malaysia, Iran, Arab Saudi, Uni Emirat Arab, Sudan, Mesir, Singapura, Aljazair, Pakistan, India, Jerman, Prancis, dan Kuwait. Kementerian Agama juga telah menyelenggarakan The $3^{\text {rd }}$ International Conference on Islamic Media di Jakarta tanggal 3-5 Desember 2013. Sebelumnya perhelatan International Conference on Islam, Civilization and Peace telah dilaksanakan di Jakarta tanggal 22 April 2013.

Jenis pelembagaan Islam lain yang tak kalah penting bagi penetrasi nilai-nilai keislaman yang membumi di Indonesia adalah munculnya spiritualitas atau seni Islam, mode pakaian muslim, dan bank syariah. Seni Islam menginspirasi sastrawan-sastrawan dan pemusik Muslim menciptakan genre karya sastra-profetik yang khas seperti Taufiq Ismail, Danarto, Abdul Hadi WM, Hamid Jabbar, Sutardji Chalzoum Bachri, Kuntowijoyo, Emha Ainun Nadjib, D. Zawawi Imron, Ajip Rosidi, dan Mustofa Bisri. Sementara pemusik Muslim dengan genre-nya masing-masing seperti Trio Bimbo, Rhoma Irama, Dwiki Darmawan, Haddad Alwi dan Sulis, kelompok Snada, Opick, Ungu, dan banyak lagi sampai munculnya Fathin Sidqia di X Factor 2013 yang meramaikan blantika musik Islam di Indonesia (Cf. Mastuki, 2010).

Mode busana muslim juga menampakkan gejala yang sama, bahkan lebih revolusioner. Saat ini busana Muslim sudah menjadi budaya popular di Indonesia, dalam arti sudah dipakai dan sudah diterima oleh kebanyakan orang Indonesia. Bahkan busana jenis ini sudah menjadi komoditas. Para desainer Muslim mulai beralih ke busana-busana muslim dan menampilkan hasil kreasi mereka dalam berbagai perhelatan fashion show yang diadakan di berbagai tempat bergengsi. Kebanyakan desainer ini adalah wanita dan beberapa diantaranya selebritis, misalnya Ida Royani, Ida Leman, Sitoresmi Prabuningrat, Anne Rufaidah, Fenny Mustafa, Irna Mutiara, Iva Latifah, Monika Jufry, dan Dian Pelangi.

Seakan melengkapi 'islamisasi' yang terus berlangsung itu, pembentukan Bank Muamalat Indonesia (BMI) pada 1991 menjadi titik awal perkembangan ekonomi syariah yang luar biasa perkembangannya di Indonesia. Takaful, BMT, bank syariah, reksadana dan asuransi syariah berdiri bak cendawan di musim hujan. Kini hampir semua bank milik pemerintah dan swasta memasang logo "syariah".

Melihat perkembangan itu semua, kita boleh optimis kini dan ke depan tampaknya nilai-nilai Islam yang terkandung dalam akidah, syari'ah dan mu'amalah bakal semakin kokoh dan menjadi budaya bangsa Indonesia. Menteri Agama Suryadharma Ali melihat perkembangan demikian ini dalam beberapa kesempatan menghimbau agar Islam Indonesia menjadi tuan rumah bagi muslim dunia. Kajian Islam di Indonesia bisa menjadi 
trade-mark bagi bangsa Indonesia yang akan menjadi daya tarik bagi bangsa-bangsa lain belajar Islam. Kepercayaan internasional seperti disinggung sepintas di atas dapat menjadi amunisi penting bagi sarjana Muslim Indonesia 'menjajakan' potensi Islam secara luas. Disini lagi-lagi posisi perguruan tinggi menjadi penting untuk menjadikan Islam Indonesia sebagai lahan kajian baru, menggantikan kajian yang terlalu condong ke belahan dunia Islam Timur Tengah.

Meskipun demikian, optimisme ini hendaknya menyadarkan kita bahwa perjuangan Islam belum selesai. Islamisasi tak pernah berhenti. Ibarat mendayung, biduk tak bertepian. Indonesia yang Islam atau Islam yang mengindonesia tetap menjadi cita-cita. Semoga.

\section{DAFTAR PUSTAKA}

\section{A. Buku dan Artikel}

Anwar, M. Syafi'i, Pemikiran dan Aksi Islam Indonesia Sebuah Kajian Politik tentang Cendekiawan Muslim Orde Baru, (Jakarta: Paramadina, 1995)

Azra, Azyumardi, "Contemporary Islamic Renewal in Indonesia", Al-Jamiah Journal on Islamic Studies IAIN Sunan Kalijaga, No. 59/1996

Azra, Azyumardi, Jaringan Ulama Timur Tengah dan Kepulauan Nusantara Abad XVII dan XVIII, (Bandung: Mizan, 1994).

Azra, Azyumardi, Pendidikan Islam: Tradisi dan Modernisasi Menuju Milenium Baru, (Jakarta: Logos, 1999)

Azra, Azyumardi, "Cultural Pluralism In Indonesia: Continuous Reinventing of Indonesian Islam in Local, National and Global Contexts", Paper presented as a Keynote Speech at Annual Conference on Islamic Studies (ACIS) "Reinventing Indonesian Islam", Banjarmasin, South Kalimantan, Indonesia, 1-4 November 2010

Bamualim, Chaider S. (ed.), A Portrait of Contemporary Indonesian Islam, (Jakarta: Pusat Bahasa \& Budaya UIN Jakarta dan Konrad-Adenaeur-Stiftung (KAS), 2005)

Effendy, Bahtiar, Islam dan Negara: Transformasi Pemikiran dan Praktek Politik Islam di Indonesia, (Jakarta: Paramadina, 1998)

Kuntowijoyo, "Muslim Kelas Menengah Indonesia dalam Mencari Identitas, 1910-1950", Prisma, No. 11 Th. 1985

Kuntowijoyo, Identitas Politik Umat Islam, (Bandung: Mizan, 1997)

Kuntowijoyo, Muslim Tanpa Masjid, (Bandung: Mizan, II/2001)

Kuntowijoyo, Paradigma Islam Interpretasi untuke Aksi, (Bandung: Mizan, 1993)

Latif, Yudi, Inteligensia Muslim dan Kuasa: Genealogi Inteligensia Muslim Indonesia Abad ke-20, (Bandung: Mizan, 2005)

M.C. Ricklefs, Sejarah Indonesia Modern (terj.), (Yogyakarta: Gadjah Mada University Press, 1991)

Madjid, Nurcholish, Islam Kemodernan dan Keindonesiaan, (Bandung: Mizan, XII/1998) 
Madjid, Nurcholish, Pikiran-Pikiran Nurcholish "Muda": Islam Kerakyatan dan Keindonesiaan, (Bandung: Mizan, 1996)

Madjid, Nurcholish, Tradisi Islam: Peran dan Fungsinya dalam Pembangunan di Indonesia, (Jakarta: Penerbit Paramadina, 1997)

Madjid, Nurcholish "Mencari Akar-Akar Islam Bagi Pluralisme Modern: Pengalaman Indonesia", dalam Mark R Woodward (ed), Jalan Baru Islam: Memetakan Paradigma Mutakhir Islam Indonesia, (Bandung : Mizan, 1998).

Mahrus, Erwin dkk, Shaykh Ahmad Khatib Sambas, (Pontianak: Untan Press, 2003)

Mastuki \& Ishom el-Saha (Ed.), Intelektualisme Pesantren, 3 jilid (Jakarta: Diva Pustaka, III/2006)

Mastuki HS, Kebangkitan Kelas Menengah Santri, (Jakarta: Pustaka Dunia, 2010)

Mastuki HS, "Mainstreaming Pendidikan Islam dan Masa Depan Islam Indonesia", makalah tidak dipublikasikan, 2013

Moedjianto, Konsep Kekuasaan Jawa: Penerapannya oleb Raja-raja Mataram, (Yogyakarta: Kanisius, 1987)

Munawar-Rachman, Budhy, "Islam Indonesia-Nusantara: Dialektika, Pluralitas Budaya dan Pergumulan Menemukan Jati Diri”, Makalah disajikan pada forum ACIS ke-10 di IAIN Banjarmasin tahun 2010

Mun'im DZ, Abdul, "Islam Nusantara: Antara Prasangka dan Harapan yang Tersisa", makalah yang dipresentasikan di ACIS ke-10 tahun 2010 di Banjarmasin (koleksi pribadi, non-published)

Purwadi, Sejarah Raja-Raja Jawa, (Yogyakarta: Media Ilmu, 2007)

Rahardjo, Dawam, "Basis Sosial Pemikiran Islam di Indonesia Sejak Orde Baru”, Prisma, no. 3, Maret 1991

Rahardjo, M. Dawam, Intelektual, Intelegensia dan Prilaku Politik Bangsa, (Bandung: Mizan, 1993)

Sunyoto, Agus, Atlas Wali Songo, (Jakarta: Pustaka IIMaN \& LTN NU, 2012)

\section{B. Website}

www.kemenag.go.id

www.pendis.kemenag.go.id

Detik.com

Republika.online (ROL)

Kompas.com

Gatra.com

Wordpress.com

Wikipedia.org 